\title{
Iplementation of E-Commerce Systems a new challenge for Standardisation Agencies of Ballcan Countries as Kosovo, Albania and Bosnia Hercegovina
}

\author{
Dr. Genci Sharko
}

Lecturer, Polytechnic University of Tirana, Electrical Engineering Faculty

\author{
Dr. Mirlinda Karcanaj
}

Lecturer, University of Tirana, Economic Faculty

\section{Dr. Anni Dasho}

Lecturer, European University of Tirana, Economic and Information Technology Faculty

\section{Doi:10.5901/ajis.2015.v4n3s1p343}

\section{Abstract}

\begin{abstract}
In order to be able to carry out the standards implementation process with limited human resources, the standardizations agencies need to established the Electronic Standardization Management and Information System. The Standardization Management and Information System (SMIS) is the software tool for the management of the national and international standards development process. All relevant and related standards document information need to be connected between each other. A functional ecommerce portal for standards marketing need to have in background two functional subsystems: Standardization Management Information System (SMIS) and Sales System. The purpose of this system is to provide all Standardizations Agencies with a Standard Management Information System (SMIS) that establishes a publicly accessible platform and interface for users to access national/international standards, and to coordinate standards information sharing between government institutions and stakeholders.
\end{abstract}

Keywords: Standardization Management Information System (SMIS), National/International Standards, electronic services.

\section{Introduction}

The Institutes for Standardisation of Kosovo, Albania and Bosnia and Herzegovina are the national organisations for standardisation established as an autonomous institution of governmental administration for affairs related to the standardisation area. Basic activities of these institutions are related to the Law on Standardisation of Kosovo, Albania and Bosnia and Herzegovina. The scope of jurisdiction is clearly stated in the Law on establishment the Institute for Standardisation of three countries Kosovo, Albania and Bosnia and Herzegovina.

Usually the Institute for Standardisation is responsible for establishing, strengthening, developing and promotion of the standardisation system of those Countries. It proposes the strategy of standardisation, prepares and publishes standards of the countries, represents and acts on behalf of Countries Standardisation Institutes in International, European and other interstate organisations for standardisation and performs other tasks that originate from international agreements and memberships in the organisations. It participates in preparing technical regulations, establishes and develops the national information system for standardisation, organizes and provides special education of personnel in standardisation area.

The Standardization Institute E-Commerce system will expand web functionality of the information system toward the new electronic services that are accessible through the website of Standardization Institute. The Standardization Institute E-Commerce portal will explore the possibility for electronic payments services. The E-Commerce system will integrate the existing SMIS application, upgraded for this purpose, new sales system implemented into SMIS system as part of it and website application. The new E-Commerce portal will provide services for different user types, in reliable and security level [1], [2], [3]. 


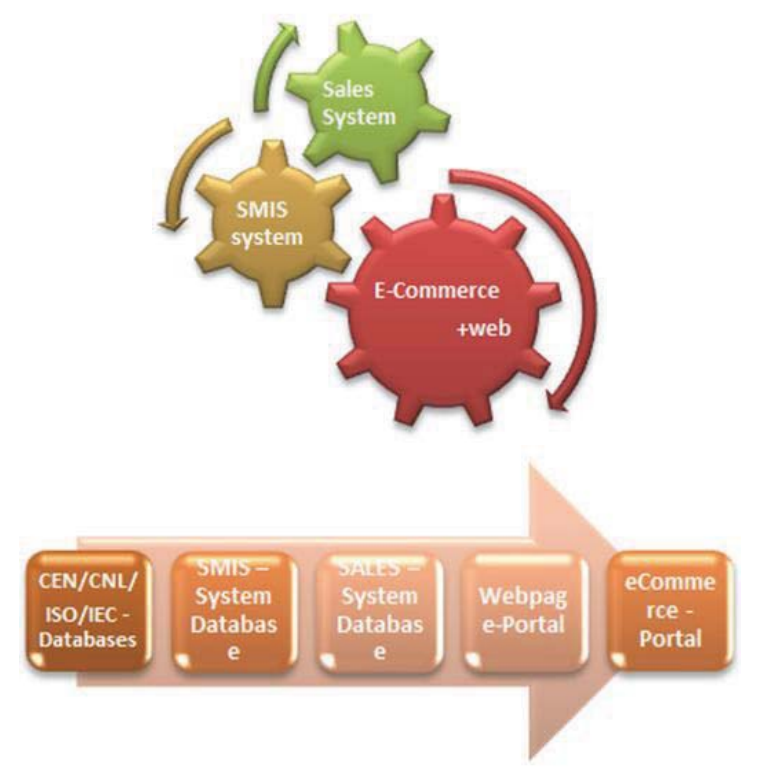

Figure 1: The Standardization Institute Sales system and SMIS integrated into E-Commerce portal

The E-Commerce Business Objectives to be achieved through the application:

- To improve the transparency and access to information on preparation of standards at National, European and International levels. To improve the information system for standardisation to be compatible with International and European Organisations for Standardisation.

- Improve the performance, using new ways of working more intelligently by using state-of-the-art Information and Communication Technology (ICT).

- The establishment of fully operational information system will improve the quality of services provided to the customers and will ensure the successful participation of the Standardization Institute for the future work in the International and European standardisation organisations.

- Compliance with the good standardisation practice in EU is a necessity. The proper use and implementation of CEN/CENELEC information (exchanged files) requires establishment of relative database with appropriate defined access rights and traceability.

The Standardization Management and Information System (SMIS) is the software tool for the management of the national and international standards development process. In order to be able to carry out the standards implementation process with limited human resources, the Standardization Agency need to establish the Electronic Standardization Management and Information System. All relevant and related standards document information need to be connected between each other.

The following diagram describes in generally SMIS system modules to be implemented at for a Standardization Agency.

The purpose of this system is to provide the Standardization Institution with a Standard Management Information System (SMIS) that establishes a publicly accessible platform and interface for users to access National standards, and to coordinate standards information sharing between government institutions and stakeholders. The SMIS enable the management of national/international standards life cycle. The standards database needs to be developed in the national language and in English, Serbian when it's needed as well [1], [2].

The SMIS software system already provides the following main functionalities and managements:

- Managing National Standards/Standardization Documents information, actions and phases;

- Managing International and European Standards/Standardization Documents information;

- Managing National Technical Committees information, members, work, decisions, mirror TCs ; 
- Managing the National Technical Committees information;

- Managing International and European Technical Committees information;

- Managing Directives information;

- Managing translators and translation process;

- Export of information in .txt, .doc, .xls and .pdf format;

- Automatic generation of Standards/ Standardization Documents Cover Page in accordance with National Standardization Institute template and title translation of the standard/standardization document;

- Managing Standards Prices and Price Groups;

- Managing of Voting Process;

- Managing Enterprises/Stakeholders;

- Managing users and users rights;

- Different Reports for notification and fast replies to questions from society/industry purposes;

\section{E-Commerce Business Databases and Applications System Integrations}

Standards Management System Information (SMIS)

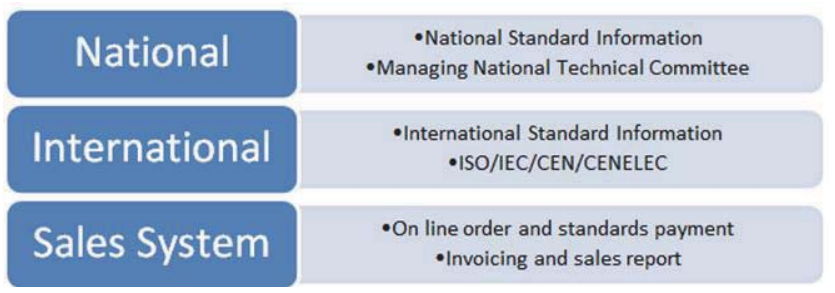

The Standardization Institute E-Commerce system will expand web functionality of the information system toward the new electronic services that are accessible through the website of Standardization Institute. The Standardization Institute ECommerce portal will explore the possibility for electronic payments services. The E-Commerce system will integrate the existing SMIS application, upgraded for this purpose, new sales system implemented into SMIS system as part of it and website application. The new E-Commerce portal will provide services for different user types, in reliable and security level [1], [2], [3].

The E-Commerce Business Objectives to be achieved through the application:

- To improve the transparency and access to information on preparation of standards at National, European and International levels. To improve the information system for standardisation to be compatible with International and European Organisations for Standardisation.

- Improve the performance, using new ways of working more intelligently by using state-of-the-art Information and Communication Technology (ICT).

- The establishment of fully operational information system will improve the quality of services provided to the customers and will ensure the successful participation of the Standardization Institute for the future work in the International and European standardisation organisations.

- Compliance with the good standardisation practice in EU is a necessity. The proper use and implementation of CEN/CENELEC information (exchanged files) requires establishment of relative database with appropriate defined access rights and traceability. 

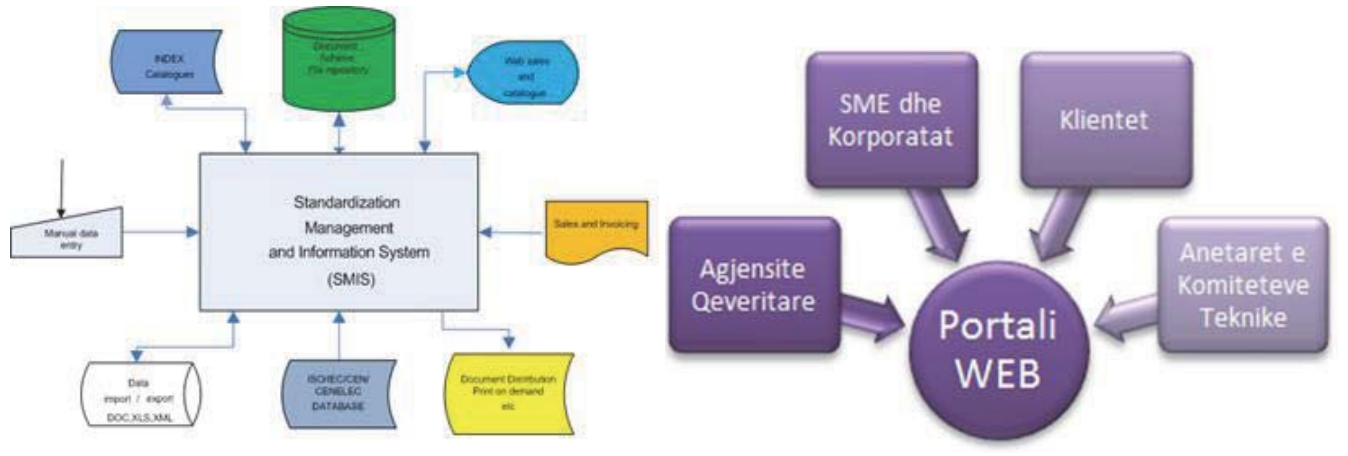

Figure 2: Standards Management System Information (SMIS) -modules and Web Portal

This system integration will provide efficient means and tools for recording and updating all data related to the standardization process. The following diagram shows the main system databases and application need to be integrated and installed in order to have a fully operated E-Commerce portal [4],[5].

Provide an efficient information services for distributing, promoting and providing customers including National Standardization Institute staff, stakeholders involved in the national standardisation activity with adequate access to standards and related information data base management system need to be integrated in one unified and relational database[1], [2], [3].

The Standardization Institute E-Commerce system will have the following general functions:

- Expanding of the Standardization Institute web site to E-Commerce portal of Standardization Institute possibilities such are electronic payment, invoicing and sales system.

- Integration on one single communication environment the e-Learning like online courses, meetings, seminars, training sessions services using the functionality of single communication environment. Integrating services portal to portal implements various used functionality for providing new electronic services.

- Integration of new functionality access control to electronic documents of Standardization Institute by controlling access to Internet portal for use by external users.

- Providing to the users with controlled and secure access to content standards.

- Providing opportunity for active reading of the documents by opening related texts and documents with hyperlinks to those relevant texts and documents.

- Digital delivery of products and services and online marketing process.

The E-Commerce application will be developed in a well-known database standard platforms to support the future workflow in National Standardization Institution and with the possibility to add/remove modules, or any other functionality without having to change or modify the entire software package. The system will be delivered and it will comply with the requirements described in the followed schematic diagrams and process described later in this document. The system will be developed all official languages of National Standardization Institution [6],[7].

\section{The Challenges of Standardisation Agency Sales System}

The new sales system will provide a more robust platform within a single standardisation relational database. The sales system will be a sub-system within the existed SMIS database. This will give to the Standardisation Agencies greater flexibility and allow improved customer service and reduced administration costs for it. The new sales system will be the driven engine for the E-Commerce services of every Standardisation Agencies (Kosovo, Albania and Bosnia \& Herzegovina). It will allow common information available to all clients and Standardisation Agencies staff.

Sales system will allow order entry directly by all customers and also by the Standardisation Agencies staff. Different sales processes will be automated within the sales system. The sales system will be powered by fully searchable text on line catalogue by searching engine. It will drive the customer to on line order placing facility. The system will allow customers to be able to register or logon into the system.

The System Sales and payment service will be integrated with the official web sites of Standardisation Agencies in order to allow a data flow for the E-Commerce web site front office services to Kosovo/Albania and Bosnia Hercegovia 


\section{SMIS and Sales systems and vice-versa.}

In case of E-Payment or E-Banking transfer the all Standardisation Agencies sales modules will be able to manage: Customer ordered standards, placing the customer orders into shopping basket, register itself (first time only) or login, options of E-Payment transfer, confirms the order to the sales system, the system will generate the pre-invoice to customer, customer E-Payment transfer, accounts department flags that order as ready for delivery, deliver electronically or by post standards order, customer notification.

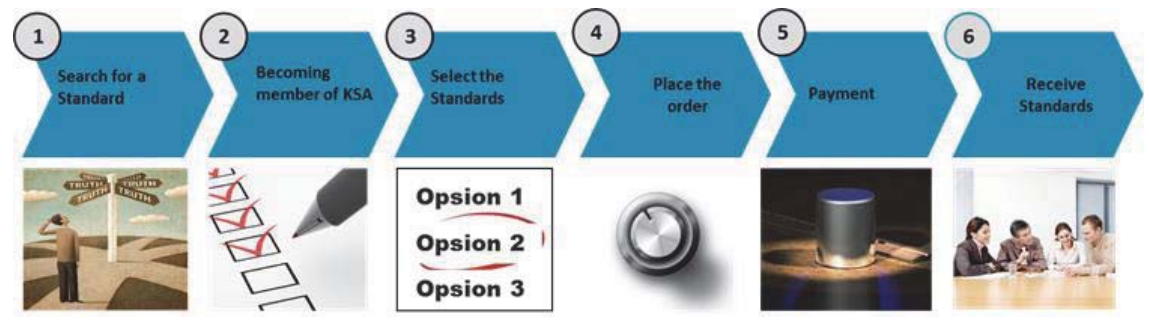

Figure 3: Sales of the Standards through WEB portal

\section{Conclusions}

Regarding EU Directives and Regulation References Module, the system will also consider the list of relevant EU Directives and regulations, as well as the references between them, and the references of European standards which are applicable for the Directive. The system will be able to consider references for standards not only in National but also in European Public Policies and regulations, or even in other countries.

The new sales system will provide a more robust platform within a single standardisation relational database. The sales system will be a sub-system within the existed SMIS database. This will give the standardization institute greater flexibility and allow improved customer service and reduced administration costs for it. The new sales system will be the driven engine for the E-Commerce services of standardization institute. It will allow common information available to all customer and standardization institute staff.

\section{References}

http://www.en.aenor.es/aenor/inicio/home/home.asp

http://www.ibf.be/

http://www.bas.gov.ba/

http://www.bds-bg.org/en

Standing Committee of the National People's Congress, Standardization Law of the People's Republic of China, 12-29-1988, http://www.lawinfochina.com/law/display.asp?id=1197

Wang Ping, Wang Yiyi, John Hill, Standardization Strategy of China-Achievements and Challenges, Economics Series, No. 107, January 2010, West Center Working Paper,

Ren Anxue, The Power of Companies, P57, Shanxi Education Press, 2010.8

Kober, N., \& Rentner, D. S. (2011). States' Progress and Challenges in Implementing Common Core State Standards. Washington, DC: Center on Education Policy. http://www.cep-dc.org/publications/index.cfm?selectedYear=2011 